\title{
Association of body shape with amount of Arabian genetic contribution in the Lipizzan horse
}

\author{
Thomas Druml $^{1}$, Michaela Horna ${ }^{2}$, Gertrud Grilz-Seger ${ }^{3}$, Maximilian Dobretsberger ${ }^{1}$, and \\ Gottfried Brem ${ }^{1}$ \\ ${ }^{1}$ Institute of Animal Breeding and Genetics, Veterinary University Vienna, Veterinärplatz 1, 1220 Vienna, \\ Austria \\ ${ }^{2}$ Department of Animal Husbandry, Slovak University of Agriculture in Nitra, Slovakia \\ ${ }^{3}$ independent researcher: Pöckau 41, 9601 Arnoldstein, Austria
}

Correspondence: Thomas Druml (thomas.druml@vetmeduni.ac.at)

Received: 22 June 2017 - Accepted: 8 January 2018 - Published: 7 February 2018

\begin{abstract}
Crossbreeding between individuals of different breeds and introgression, the transfer of genes between breeds and/or populations mediated primarily by backcrossing, have been characteristic tools used in the refinement or optimisation of practical horse breeding. In this study we analysed the genetic contribution of the Arabian horse to the gene pool of the Lipizzan horse and its association with the overall type via shape regression analysis in 158 Lipizzan horses from the Austrian federal stud farm of Piber and the Spanish Riding School. Although crossbreeding with Arabian horses took place between 1776 and 1945, we found a significant association between Lipizzan body shape $(p<0.003)$ and individual coefficients of Arabian gene proportion, which varied from 21 to $29 \%$. In order to compare and interpret the estimated Lipizzan shape transitions from Iberian type towards the oriental type, we included a sample of 32 Shagya Arabians from the Slovak National stud farm Topol'ćianky. The estimated shape transitions in Lipizzans due to an increasing proportion of Arabian genes are similar to those we observed in the population comparison study of Lipizzan and Shagya Arabian horses. The main morphometric differences due to increasing Arabian genetic contributions in Lipizzans were found in the conformation of head, neck, withers, and legs. Although selection in the Austrian Lipizzan breed favours the Iberian type, Arabian shape characteristics are still present, indicating the segregation of Arabian founder haplotypes in the population. We also demonstrated that techniques of shape analysis are able to differentiate phenotypes associated with the gene pool and can be applied for phenotypic evaluation and prediction in crossbreeding programs.
\end{abstract}

\section{Introduction}

Within the refinement processes of horse breeding, throughout the 19th century oriental horses were commonly used for crossbreeding and introgression of positive performance and character traits. Whereas the English Thoroughbred represents the current meliorator breed for warmblood sport horses, Arabian horses played this important role a century before. The Lipizzan horse is known as a classical baroque riding horse, a classification that is supported by the fact that $60 \%$ of founder genes come from baroque Spanish and Italian ancestors born in the 18th century. Nevertheless, Arabian breeding animals were used in the Lipizzan breed be- tween 1776 and 1945, and their founder gene proportion comprised about $23 \%$ in the populations of eight European Lipizzan state stud farms (Zechner et al., 2002). In a genealogical context the introgression of Arabian genes into the Lipizzan gene pool is documented by the classical sire line Siglavy, founded by an original Arabian stallion imported from Syria in 1814, and by several dam lines going back to Arabian founder mares imported between 1830 and 1865. In the 19th century the breeding of Arabian horses was supported by the Austro-Hungarian Empire at the state stud farms Rădăuți, Bábolna, and Mezőhegyes. The resulting Arabian horse, today called the "Shagya Arabian", rep- 
resents a continental Arabian, based on the crossbreeding of original Arabian stallions with Turkish, Kazakh, Moldavian, and Hungarian founder mares that were born before 1800 . From 1800 to 1934 original Arabian breeding mares and stallions were constantly imported from Syria in order to consolidate the Arabian population. Due to interactions between the Austro-Hungarian state stud farms and the imperial stud farm Lipica, both breeds, the Lipizzan and the Shagya Arabian, share a common founder pool dating to the time period from 1810 to 1865 .

The effects of Arabian genes on morphology and conformation have been the focus of practical breeding for a long time (Bilek, 1914; Schwark, 1984; Schröder et al., 2010). In the case of the Lipizzan horse, the first analysis was published by Bilek in 1914, who studied the morphological differences between Lipizzans with varying Arabian gene proportions based on anatomical body measurements. In a more recent work, Druml and Sölkner (2012) documented differences in the extent of Arabian gene proportions in the gene pools of eight European Lipizzan state stud farms of Austria, Croatia, Hungary, Italy, Romania, Slovakia, and Slovenia using pedigree analysis, where Hungarian and Romanian Lipizzans were characterised by lower genetic contributions of Arabian founder animals. In a morphologic characterisation study by means of anatomical body measurements in the same eight Lipizzan state studs, Zechner et al. (2001) could show significant morphological differences between horses of the single stud farms, which were interpreted as a result of selection in favour for specific types (riding horse or carriage horse).

The aim of our study was to document the Arabian gene pool in the current Lipizzan population of Piber and the Spanish Riding School and to test the association of the body shapes of Lipizzan horses with individual levels of Arabian genetic contributions by means of geometric morphometric (GM) methods. Furthermore, we wanted to test if GM methods based on image analyses are an appropriate tool to differentiate phenotypic traits between animals of varying Arabian genetic background. Further, we used a sample of Shagya Arabian horses from the Slovak national stud farm of Topol'čianky as a reference population for comparing estimated oriental shape transitions in the Lipizzan with the existing differences between Lipizzans and Shagya Arabians.

\section{Material and methods}

\subsection{Pedigree analyses and sampling}

In order to derive the individual Arabian gene proportions of 158 Lipizzan horses (93 stallions from the Spanish Riding School, 65 mares from the federal stud farm Piber) at a mean age of 10.9 years (minimum age $=3$; maximum age $=29$; $\mathrm{SD}=5.6$ ), we conducted a pedigree analysis using the software program ENDOG 4.6 (Gutierrez and Goyache, 2005). The pedigree included 5.004 individuals and ranged back
33 generations. The analysed horses were offspring from 63 sires and 101 dams. The mean number of offspring per sire was 2.5 and the mean number of offspring per dam was 1.6. Founder animals and their genetic contributions were determined for each animal and the single Arabian founder contributions were summed up into one coefficient $\left(f_{\mathrm{Ar}}\right)$.

For the same set of animals, which represents the actual state-owned Austrian Lipizzan breeding population, we collected standardized digital photographs following the protocol of Druml et al. $(2015,2016)$ (see Fig. S1 in the Supplement). The photos were taken by one of the authors and the imaging process was repeated several times where a minimum of two line-ups per horse were performed per session. For the selection of the pictures used, an optimal fit criterion regarding the stance of the horse (open posture) was applied by visual assessment (Fig. S1). The Arabian reference population was imaged by the same person in one session following the above-mentioned procedure in the Slovak national stud farm of Topol'čianky, where 32 Shagya Arabians (5 stallions, 27 mares) from 11 sires (mean number of 2.9 offspring per sire) at a mean age of 6.1 years (minimum age $=3$; maximum age $=17 ; \mathrm{SD}=3.2$ ) were sampled.

\subsection{Statistical analyses of shape variation}

In order to retrieve informative shape data from the standardised images, we applied a shape model that includes the coordinates of parts of the outline and 31 somatometric and anatomical landmarks. The 215 outline coordinates were defined as sliding semi-landmarks, which allow the single points to slide along the outline curve during the rotation process of the generalised Procrustes analysis (GPA). Hence the outline coordinates result in homologous-like points along a curve (Gunz and Mitteröcker, 2013) and can be compared directly to each other (Fig. 1).

Before proceeding to statistical analyses of shape data and/or variables the individual coordinates need to be normalised, as images also contain information concerning different body size, orientation, and location of the animal. Such uninformative effects can be eliminated or corrected by means of a generalised Procrustes superimposition, which scales, rotates, and centres every single specimen onto the mean configuration of the sample. This statistical procedure eliminates non-shape-associated variation by superimposing landmark configurations using least-squares estimates for translation and rotation parameters. First, the centroid of each configuration is translated to the origin, and configurations are scaled to a common unit size. The centroid is defined as the mean of all $x$ and $y$ values from all coordinates. Each shape is characterised by its size, called centroid size. This variable is the square root of the sum of all squared distances from each landmark to the centroid. If all $x$ and $y$ coordinates of the landmarks are divided through centroid size, the resulting specimens are of unit size 1. Finally, the configurations are optimally rotated to minimise the squared differ- 

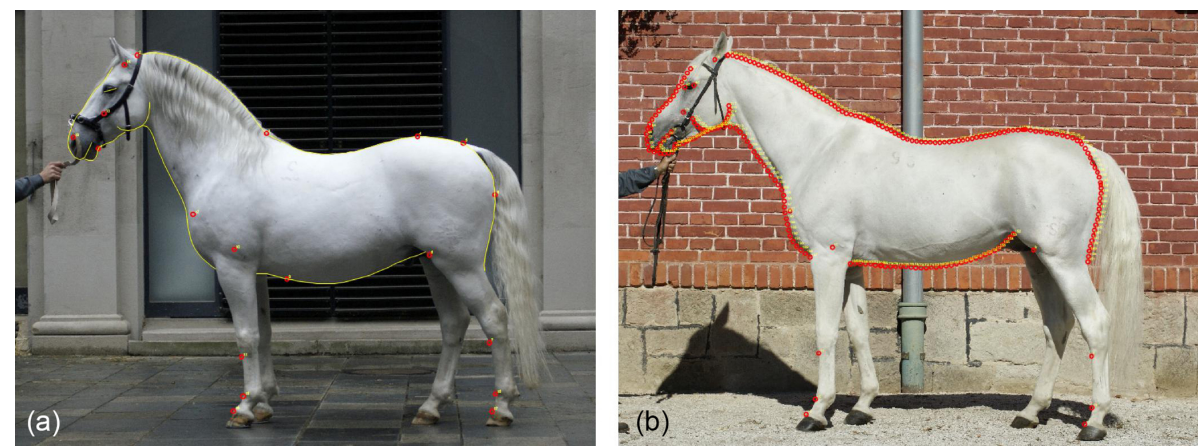

Figure 1. Shape model for phenotyping the horses. On the Lipizzan stallion (a) 31 single landmarks and eight outline curves (yellow line) are shown. The outline curves were transformed into single sliding semi-landmarks, which are illustrated on the Shagya Arabian stallion in panel (b) (illustrations and photos by Thomas Druml).

ences between corresponding landmarks, which is also called Procrustes distance $d$ (Rohlf and Slice, 1990). The process is iterated to compute the mean shape (for further information see Druml et al., 2015, 2016).

At the end of this procedure, the original coordinate data are replaced by substitute Cartesian coordinates (shape coordinates; Bookstein, 1991), as they vary around their own sample mean, and are corrected for effects of scale (body size), for effects of orientation, and for effects of location of the original specimens. The resulting shape coordinates $((k$ landmarks $) \times(n$ dimensions $))-$ four Procrustes residuals, projected on a tangential space, were used for the determination of the body shape traits using principal component analysis (PCA). The axes of principal components (PCs) can be described, quantified, and visualised by coordinate transformations named thin-plate splines (linear combinations of shape coordinates) of horse shapes moving along each PC axis. Procrustes rotation and graphical representations of horse shapes were performed with the software program tpsRelw, version 1.53 (Rohlf, 2013).

To evaluate the association of Arabian genetic contribution with the body shape of 158 Lipizzan horses, we applied socalled shape regressions, in which shape coordinates were regressed onto the individual Arabian gene proportions $\left(f_{\mathrm{Ar}}\right)$. Further, we recalculated gene proportion-associated Lipizzan horse shapes along the established regression curve for (a) a model horse with $15 \%$ Arabian genetic contribution and for (b) a model horse with $35 \%$ Arabian genetic contribution in order to visualise the aspects of shape encoded in oriental and Iberian or baroque Lipizzans. The shape regression was performed with the software program tpsRegr, version 1.40 (Rohlf, 2011).

Descriptive statistics were calculated using the procedures proc freq and proc means of the SAS software package, version 9.1 (SAS Institute, 2009). For the analysis of differences in shape between 158 Lipizzan horses and 32 Shagya Arabians, we applied a generalised linear model (glm) as follows:

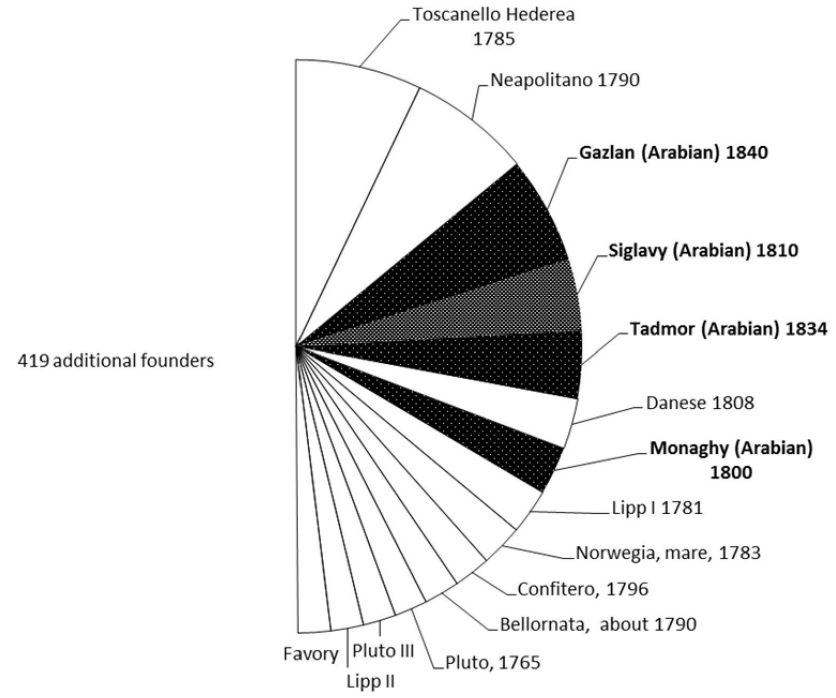

Figure 2. The most important founder animals of the Lipizzan population from the federal stud farm of Piber and the Spanish Riding School defining $50 \%$ of the gene pool. Among these 15 founders, four Arabian stallions (marked by bold letters) together contribute $16.6 \%$ of genes to the total founder gene pool.

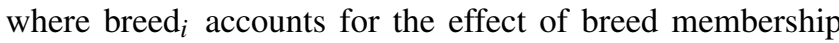
(Lipizzan/Shagya Arabian), age class ${ }_{j}$ takes differences due to age and physical development (seven age classes: 3 to 5 years; 6 to 7 years; 8 to 10 years; 11 to 14 years; 15 to 17 years; 18 to 21 years; more than 22 years) into account, and $\operatorname{sex}_{k}$ stands for the effect of sexual dimorphism (stallion or mare). In addition, we also tested the interactions between breed, age class, and sex in the model. The generalised linear model analysis was performed using the software package SAS, v. 9.10 (SAS Institute, 2009).

$Y_{i j k l m}=\mu+\operatorname{breed}_{i}+\operatorname{age~class~}_{j}+\operatorname{sex}_{k}+\varepsilon_{i j k l}$, 
Table 1. The proportion of genetic contribution of Arabian founders in the Lipizzan population of the Austrian federal stud farm of Piber.

\begin{tabular}{lll}
\hline Breed & Gene proportion & Founder animals \\
\hline Anglo-Arabian & $0.08 \%$ & 1 \\
Arabian & $2.55 \%$ & 15 \\
Original Arabian & $20.12 \%$ & 22 \\
Purebred Arabian & $0.08 \%$ & 3 \\
Shagya Arabian & $1.37 \%$ & 27 \\
Tunisian & $0.09 \%$ & 1 \\
Turco-Arabian & $1.73 \%$ & 3 \\
\hline & $26.01 \%$ & 72 \\
\hline
\end{tabular}

\section{Results}

\subsection{Arabian gene pool}

The pedigree used for this analysis was maximally 33 generations long. In the 12th generation $90 \%$ of ancestors were known and in the 17th generation the percentage of known ancestors dropped beyond $50 \%$. In total the Lipizzan gene pool of this sample was defined by 434 founder animals, whereas the 15 most influential founder animals, including four Arabian stallions, accounted for $50 \%$ of the pool (Fig. 2).

The mean genetic contribution of Arabian founders to the gene pool of the Lipizzan population of the federal stud farm of Piber and the Spanish Riding School achieved, in total, $26 \%$, and it was contributed by 72 founder animals (22 mares contributing $1.4 \%$ and 50 stallions contributing $24.6 \%$ ). Of the Arabian genes, $20.1 \%$ were due to imported original Arabians from Syria between the years 1800 and 1865. Most of these 22 original Arabians were the founder animals for the Shagya Arabian breed in the state stud farms of the Austro-Hungarian monarchy at the same time. Furthermore, 32 Shagya Arabians contributed $1.4 \%$ of genes within the time period from 1817 to 1934 . The remaining $4.5 \%$ of the Arabian gene pool was contributed by so-called Arabian founders (15 horses), Anglo-Arabian founders (one horse), purebred Arabians (three purebred Arabian stallions), one Tunisian stallion, and three Turco-Arabian stallions (see Table 1; Table S1 in the Supplement). On an individual basis, the Arabian genetic contributions varied from 21.0 to $29.0 \%$ $(\mathrm{SD}=1.04 \%)$ in the sample of 158 Lipizzan horses.

\subsection{Shape variation}

The GPA of coordinate data from 158 Lipizzans and 32 Shagya Arabians resulted in 189 shape variables (PCs), from which 17 PCs explained $95 \%$ of total shape variation (Table 2). According to the glm analysis, 12 of these 17 PCs remained uninformative ( $R^{2}$ values for PC1, PC5, PC6, and PC9 to PC17 were smaller than 0.2 ), whereas highly significant $(p<0.01)$ effects were found for the effects breed (PC2,
PC3), sex (PC7), and age class (PC3, PC4, PC7). Significant $(p<0.05)$ factor interactions were found for breed $\times$ sex (PC2, PC3, PC7, PC13), breed $\times$ age (PC11, PC17), and age $\times$ sex $(\mathrm{PC} 7, \mathrm{PC} 11, \mathrm{PC} 12)$, whereas PC11, PC12, PC13, and $\mathrm{PC} 17$ were uninformative $\left(R^{2}\right.$ values $\left.<0.2\right)$ and explained in total only $2.85 \%$ of the phenotypic shape variation.

The largest shape differences were found for PC2 (explaining $17.5 \%$ of shape variation) and PC3 (explaining $9.5 \%$ of shape variation) for the breed effect $(p<0.001)$ discriminating Lipizzans from Shagya Arabians. The effect of age class was significant $(p<0.01)$ for the variables PC3, PC4 (explaining $7.2 \%$ of shape variation), and $\mathrm{PC} 7$ (explaining $3.6 \%$ of shape variation). The sex effect was significant $(p<0.001)$ for PC7.

For the shape variables PC1 (explaining $36.0 \%$ of shape variation), PC5 (explaining $5.3 \%$ of shape variation), and PC6 (explaining $4.3 \%$ of shape variation) no significant results could be derived by the linear model as these three variables mostly accounted for individual posing differences (PC1 for neck posture; PC5 and PC6 for leg and stance posture).

Significant $(p<0.05)$ interactions for breed and sex were found for the variables PC2, PC3, and PC7, which contain information for differences between stallions and mares from both breeds (Fig. 3).

The scatter plot for PC3 and PC4 in Fig. 3 shows that younger Shagya Arabians ( $<6$ years) cluster far away from Lipizzans and older Shagya Arabians, whereas the Lipizzans overlap with older Shagya Arabians. Whereas for the interaction of breed and age class no reasonable results were derived (except for PC11 and PC17, both only explaining $1.8 \%$ of shape variation), the interaction of sex and age class was significant for PC7.

The mean shapes for Lipizzans and Arabians are shown in Fig. 4 and illustrate the typical conformation of the two breeds. The mean Lipizzan configuration is characterised by a heavier head with a tendency toward a ram-shaped profile; a muscled, well curved neck; and a curved top line. The withers are less expressed and the hindquarters are well muscled. The mean Shagya Arabian configuration shows a clear concave head profile with pronounced cheekbones. The withers are long and well expressed; the back is straight with a highpositioned tail. The detailed shape differences are illustrated in Fig. 4c, where the arrows indicate the landmark deviations of the mean Arabian shape from the mean Lipizzan shape. The main deviations were found in the conformation of neck and head, followed by the withers and the loans. Whereas the slope of shoulder, hip bone, and neck (neck pose/ankle) was similar in both mean configurations, we can observe that in the Arabian shape the extremities were longer (Fig. 4c). 
Table 2. Proportion of shape variance explained by PC (Var. explained); coefficient of determination of the linear model $\left(R^{2}\right)$; levels of significance for the fixed effects breed, sex, and age and for the interactions of breed and sex, breed and age, and sex and age from the linear model.

\begin{tabular}{lllllllll}
\hline Variables & Var. explained & $R^{2}$ & Breed & Sex & Age & Breed $\times$ sex & Breed $\times$ age & Sex $\times$ age \\
\hline PC1 & 35.95 & 0.20 & n.s. & n.s. & n.s. & n.s. & n.s. & n.s. \\
PC2 & 17.46 & 0.58 & 0.0001 & n.s. & n.s. & 0.0500 & n.s. & n.s. \\
PC3 & 9.54 & 0.67 & 0.0001 & n.s. & 0.0007 & 0.0300 & n.s. & n.s. \\
PC4 & 7.21 & 0.29 & n.s. & n.s. & 0.0058 & n.s. & n.s. & n.s. \\
PC5 & 5.26 & 0.18 & n.s. & n.s. & n.s. & n.s. & n.s. & n.s. \\
PC6 & 4.32 & 0.13 & n.s. & n.s. & n.s. & n.s. & n.s. & n.s. \\
PC7 & 3.63 & 0.46 & n.s. & 0.0001 & 0.0068 & 0.0508 & n.s. & 0.0001 \\
PC8 & 2.62 & 0.23 & n.s. & n.s. & n.s. & n.s. & n.s. & n.s. \\
PC9 & 1.81 & 0.13 & n.s. & n.s. & n.s. & n.s. & n.s. & n.s. \\
PC10 & 1.61 & 0.20 & n.s. & n.s. & 0.0370 & n.s. & n.s. & n.s. \\
PC11 & 1.33 & 0.17 & n.s. & n.s. & n.s. & n.s. & 0.0250 & 0.0108 \\
PC12 & 1.02 & 0.12 & n.s. & 0.0255 & n.s. & n.s. & n.s. & 0.0402 \\
PC13 & 0.82 & 0.20 & 0.0340 & 0.0418 & n.s. & 0.0362 & n.s. & n.s. \\
PC14 & 0.79 & 0.11 & n.s. & n.s. & n.s. & n.s. & n.s. & n.s. \\
PC15 & 0.68 & 0.12 & n.s. & n.s. & n.s. & n.s. & n.s. & n.s. \\
PC16 & 0.53 & 0.11 & n.s. & n.s. & n.s. & n.s. & n.s. & n.s. \\
PC17 & 0.50 & 0.17 & n.s. & n.s. & n.s. & n.s. & 0.0359 & n.s. \\
\hline
\end{tabular}

n.s.: not significant.
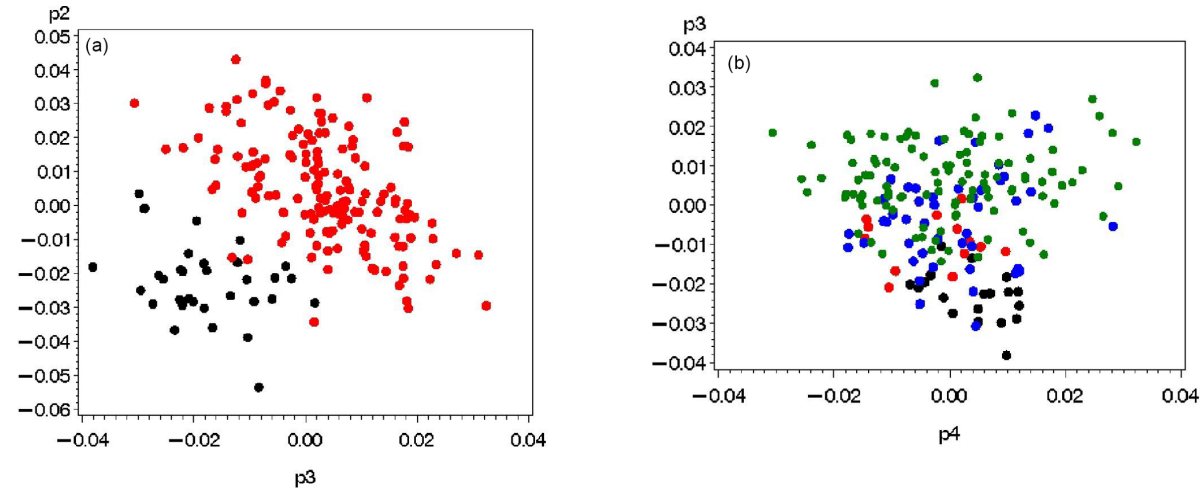

Figure 3. Scatter plot of shape variables and plot of PC2 and PC3 containing 158 Lipizzan and 32 Shagya Arabian horses (a) (red: Shagya Arabian; black: Lipizzan). (b) The scatter plot for PC3 and PC4 of the same sample (black: Shagya Arabian younger than 6 years; red: Shagya Arabian older than 6 years; blue: Lipizzan younger than 6 years; green: Lipizzan older than 6 years) is shown.

\subsection{Shape regression}

Although the variation in the Arabian gene proportions from 21 to $29 \%$ can be considered low, a significant association between the Arabian genetic contribution $\left(f_{\mathrm{Ar}}\right)$ and the shapes of Lipizzan horses could be documented in the shape regression $(p<0.003)$. The regression-curve-based estimates of Lipizzan shapes with (a) $15 \%$ Arabian gene proportion and (b) $35 \%$ Arabian gene proportion are shown in Fig. 5. The differences between both shape estimates indicated similar deviations as shown for observed shape transitions between the Lipizzan sample and the Shagya Arabian sample in Fig. 4c. Major phenotypic characteristics for the Iberian or baroque type could be observed in the speci- men (Fig. 5b), for which the estimated shape showed a wellmuscled, well curved top line; a heavier, ram-shaped head profile; and a clear quadratic format. The counterpart, the oriental Lipizzan shape (Fig. 5a), was characterised by a smaller head with a linear nose profile; clearly visible withers; a long, straight back; and a rectangular format.

\section{Discussion}

The mean Arabian gene proportions in the stud farm population of Piber did not substantially change throughout the last 20 years, as Zechner et al. (2002) calculated a nearly identical contribution of $26.2 \%$ at the population level. The major 

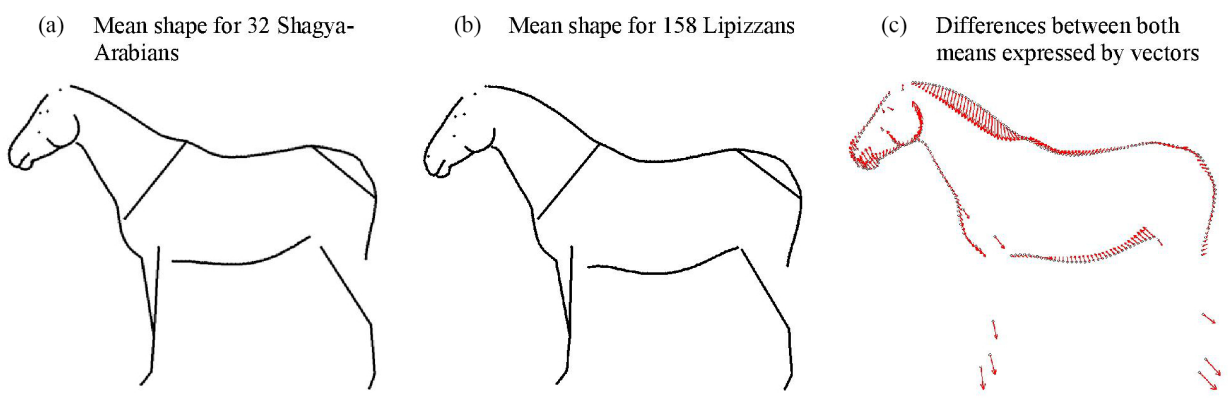

Figure 4. Mean shapes for 32 Shagya Arabians and 158 Lipizzan horses. The differences in landmark configurations between both mean shapes are shown in panel (c) expressed by vectors, which illustrate the shape transitions from Lipizzan to Shagya Arabian phenotype.
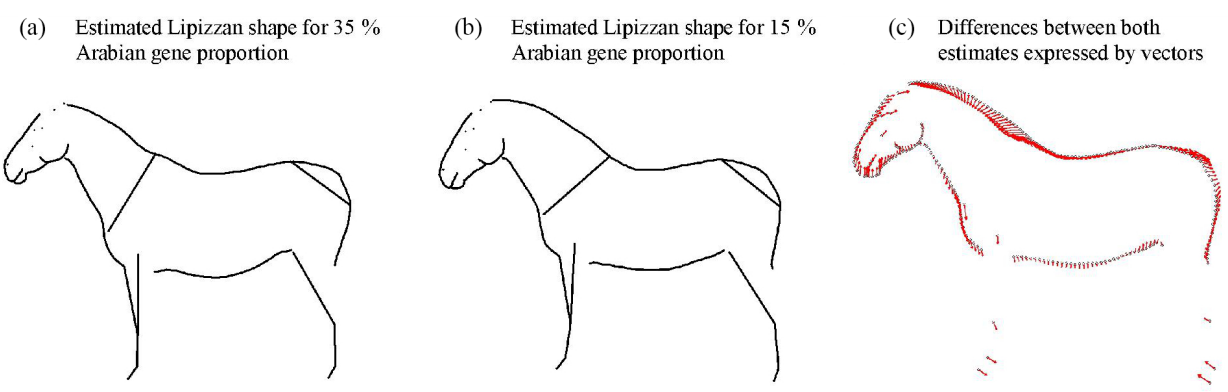

Figure 5. Estimated Lipizzan shapes along the regression curve for the (a) $35 \%$ Arabian gene proportion and (b) $15 \%$ Arabian gene proportion. The differences in landmark configurations between both estimates are shown in (c) expressed by vectors, which illustrate the shape transitions between the two specimens.

part of Arabian genes (21.2\%) in the current Austrian Lipizzan population is derived from original Arabian founders imported from Syria from 1800 to 1865 . The gene pool calculated in this study supports the previous findings of Druml and Sölkner (2012), in which the highest levels of Arabian genes were documented in the stud farms Lipica $(28.1 \%)$, Piber $(26.2 \%)$, and Monterotondo (26.0\%). The breeding objectives in these three stud farms are defined by the classical dressage riding horse, whereas the Hungarian and Romanian Lipizzan populations represent multipurpose carriagedriving horses and are characterised by lower Arabian gene proportions varying between $17.4 \%$ (Beclean and Făgăraş) and $22.7 \%$ (Szilvásvárad). The current mean Lipizzan shape of Piber as described using the Procrustes analysis, represents the classical Iberian or baroque riding horse type and is significantly different from the Shagya Arabian population of the stud farm Topol'čianky.

Although the Lipizzan population mean represents the Iberian or baroque type and the crossbreeding events with Arabian horses took place between 1776 and 1945, we were able to detect an association of Arabian gene proportions $\left(f_{\mathrm{Ar}}\right)$ with body shape using techniques of shape analysis. The results from our shape regression were in concordance with the findings of Bilek (1914), whose study was based on anatomical body measurements. It should be noticed that in this work crossbreeding products from the first to the third backcross generation were used. Bilek (1914) could demonstrate clear effects between (a) Lipizzan horses with more than $40 \%$ Arabian gene proportion, (b) Lipizzan horses with $20 \%$ to $40 \%$ Arabian gene proportion, and (c) purebred Lipizzans (less than $20 \%$ Arabian gene proportion) with regard to the height, format, head morphology, neck morphology, and conformation of croup. In our study the main characteristics of higher Arabian gene proportions were found in conformation of the head, neck, withers, and extremities.

Previous analyses of shape variation and conformation judging preferences in the Lipizzan population of Piber (Druml et al., 2015, 2016) demonstrated that the classical Iberian or baroque Lipizzan type represents the ideal breeding goal. The advantage of this image-based morphometric approach over conventional linear measuring methods is that the retrieved model horses can be easily understood and can be used for the adjustment of conformation scoring protocols and/or breeding goals in the context of breeding programs.

\section{Conclusions}

From the results of this study we can assume that an underlying conserved oriental genotype is responsible for the shape differences shown between Iberian and oriental Lipizzan horse types. The presented phenotyping and analysing method can be used for identifying major effects of genetic 
introgression and it can be used to predict transitions of conformation with increasing and decreasing genetic contributions of foreign breeds.

Data availability. Data are available upon reasonable request.

\section{The Supplement related to this article is available online at https://doi.org/10.5194/aab-61-79-2018-supplement.}

Author contributions. TD and GGS designed the experiments and TD, MD, and MH carried them out. MH and TD analysed the data and GGS and TD prepared the paper.

Competing interests. The authors declare that they have no conflict of interest.

Acknowledgements. The authors wish to thank the Austrian Research Promotion Agency (FFG) and Xenogenetik for financial support and the federal stud farm of Piber and the Spanish Riding School in Vienna and the National stud farm Topol'ćianky for assistance and cooperation.

Edited by: Manfred Mielenz

Reviewed by: four anonymous referees

\section{References}

Bilek, F.: Über den Einfluß des arabischen Blutes bei Kreuzungen, mit besonderer Hinsicht auf das Lipizzanerpferd, Sonderdruck aus dem Jahrbuch für wissenschaftliche und praktische Tierzucht, 249-256, Prag, 1914.

Bookstein, F.: Morphometric tools for landmark data: geometry and biology, Cambridge University Press, Cambridge, UK, 1991.

Druml, T., Dobretsberger, M., and Brem, G.: The use of novel phenotyping methods for validation of equine scoring results, Animal, 9, 928-937, 2015.

Druml, T., Dobretsberger, M., and Brem, G.: Ratings of equine conformation - new insights provided by shape analysis using the example of Lipizzan stallions, Arch. Anim. Breed., 59, 309-317, 2016.
Druml, T. and Sölkner, J.: Die Gründerpopulation der Lipizzanerrasse und deren Zuchtgeschichte anhand von Genanteilen, in: Lipizzaner im Spiegel der Wissenschaft, Verlag der Österreichischen Akademie der Wissenschaften, Hg. Brem, G., 153-193, Wien, 2012.

Gunz, P. and Mitteroecker, P.: Semilandmarks: a method for quantifying curves and surfaces, Hystrix, 24, 103-109, 2013.

Gutierrez, J. P. and Goyache, F.: A note on ENDOG: a computer program for analysing pedigree information, J. Anim. Breed. Genet., 122, 172-176, 2005.

Mitterröcker, P. and Gunz, P.: Advances in geometric morphometrics, Evolutionary Biology, 36, 235-247, 2009.

Rohlf, F. J. and Slice, D. E.: Extensions of the Procrustes method for the optimal superimposition of landmarks, Systematic Zoology, 39, 40-59, 1990.

Rohlf, F. J.: tpsRegr, shape regression, version 1.40, Department of Ecology and Evolution, State University of New York at Stony Brook, New York, USA, 2011.

Rohlf, F. J.: tpsUtil, file utility program, version 1.58, Department of Ecology and Evolution, State University of New York at Stony Brook, New York, USA, 2013.

Rohlf, F. J.: tpsDig, digitize landmarks and outlines, version 2.12, Department of Ecology and Evolution, State University of New York at Stony Brook, New York, USA, 2013.

Rohlf, F. J.: tpsRelw, version 1.53, Department of Ecology and Evolution, State University of New York at Stony Brook, New York, USA, 2013.

SAS Institute: SAS version 9.1, SAS Institute Inc., Cary, NC, USA, 2009.

Schröder, W., Stock, K. F., and Distl, O.: Genetic evaluation of Hanoverian warmblood horses for conformation traits considering the proportion of genes of foreign breeds, Archiv Tierzucht, 53, 377-387, 2010.

Schwark, H. J.: Pferdezucht, VEB Deutscher Landwirtschaftsverlag, Berlin, GER, 1984.

Zechner, P., Zohman, F., Sölkner, J., Bodo, I., Habe, F., Marti, E., and Brem, G.: Morphological description of the Lipizzan horse population, Livest. Prod. Sci., 69, 163-177, 2001.

Zechner, P., Sölkner, J., Bodo, I., Druml, T., Baumung, R., Achmann, R., Marti, E., Habe, F., and Brem, G.: Analysis of diversity of diversity and population structure in the Lipizzan horse breed based on pedigree information, Livst. Prod. Sci., 77, 137 146, 2002. 